\title{
Predictors of Weight Change in Male HIV-Positive Injection Drug Users Initiating Antiretroviral Therapy in Hanoi, Vietnam
}

\author{
Alice M. Tang, ${ }^{1}$ Heidi B. Sheehan, ${ }^{1}$ Michael R. Jordan, ${ }^{1,2}$ \\ Dang Van Duong, ${ }^{3}$ Norma Terrin, ${ }^{2}$ Kimberly Dong, ${ }^{1}$ Trinh Thi Minh Lien, ${ }^{4}$ \\ Nguyen Vu Trung, ${ }^{4}$ Christine A. Wanke, ${ }^{1,2}$ and Nguyen Duc Hien ${ }^{4}$ \\ ${ }^{1}$ Department of Public Health and Community Medicine, Tufts University School of Medicine, Jaharis 265, Boston, MA 02111, USA \\ ${ }^{2}$ Department of Medicine, Tufts University School of Medicine, Boston, MA 02111, USA \\ ${ }^{3}$ Bach Mai Hospital, Center of Pathology, Hanoi, Vietnam \\ ${ }^{4}$ National Hospital of Tropical Diseases, Hanoi, Vietnam
}

Correspondence should be addressed to Alice M. Tang, alice.tang@tufts.edu

Received 16 January 2011; Revised 9 May 2011; Accepted 9 May 2011

Academic Editor: Glenda Gray

Copyright (c) 2011 Alice M. Tang et al. This is an open access article distributed under the Creative Commons Attribution License, which permits unrestricted use, distribution, and reproduction in any medium, provided the original work is properly cited.

\begin{abstract}
We examined clinical and nutritional predictors of weight change over two consecutive 6-month intervals among 99 HIV-positive male injection drug users initiating antiretroviral therapy (ART) in Hanoi, Vietnam. The average weight gain was $3.1 \pm 4.8 \mathrm{~kg}$ in the first six months after ART and $0.8 \pm 3.0 \mathrm{~kg}$ in the following six months. Predictors of weight change differed by interval. In the first interval, CD4 $<200$ cells/ $\mu \mathrm{L}$, excellent/very good adherence to ART, bothersome nausea, and liquid supplement use were all associated with positive weight changes. Moderate to heavy alcohol use and tobacco smoking were associated with negative weight changes. In the second interval, having a CD4 count $<200$ cells/ $\mu \mathrm{L}$ at the beginning of the interval and tobacco smoking were the only significant predictors and both were associated with negative weight changes. We identified several potential areas for interventions to promote weight gain immediately after starting ART in this population. Studies are needed to determine whether improving weight prior to, or at, ART initiation will result in improved outcomes on ART.
\end{abstract}

\section{Introduction}

Access to antiretroviral treatment (ART) has expanded rapidly in many moderate-to low-income countries affected by the HIV epidemic. In addition to reducing mortality rates, ART has many favorable effects among people living with HIV (PLHIV), such as improving weight and lean body mass, particularly in patients with greater pretreatment immunological and virological compromise $[1,2]$. Several large-scale ART programs in sub-Saharan Africa indicate that malnutrition (low BMI) at the start of ART is significantly and independently associated with subsequent mortality [36], while weight gain after ART is associated with survival $[7,8]$. It is unclear whether this association is causal. Although weight changes appear to parallel the success of ART, it is unknown whether interventions to improve weight prior to or at ART initiation will improve subsequent outcomes.
In Vietnam, the number of PLHIV is estimated to be 293,000 with an HIV prevalence rate of $0.53 \%$ among adults [9]. Injection drug use (IDU) remains the main driver of HIV in Vietnam. The HIV prevalence rate among IDUs is estimated to be $30 \%$ overall, with rates of over $50 \%$ in Ho Chi Minh City and Quang Ninh [10]. In Hanoi, the most recent estimates of HIV among IDUs are around 25\% [9]. Rapid scale-up of ART in Vietnam began in 2005 with support from the Vietnam Ministry of Health, the United States President's Emergency Plan for AIDS Relief (PEPFAR), and the Global Fund. To our knowledge, no studies are published on the nutritional outcomes of ART initiation in Vietnam.

The primary objective of this analysis was to determine predictors of weight change six to 12 months after initiation of ART among IDUs in Hanoi. Our results will help develop and determine the appropriate timing of targeted nutritional interventions in Vietnam, paving the way for future trials to test the impact of improving weight on ART outcomes. 


\section{Methods}

2.1. Study Population. The HIV/AIDS outpatient clinic at the National Hospital of Tropical Diseases (NHTD) in Hanoi, Vietnam is a PEPFAR-supported clinic providing ART to approximately $800 \mathrm{HIV}$-infected patients. Between August 2006 and December 2008, 100 HIV-positive, ARTnaïve patients were recruited from the outpatient clinic at NHTD into an ongoing longitudinal study on the causes and consequences of malnutrition in HIV-infection. Patients were eligible if they were HIV seropositive, between the ages of 18 and 65, had a history of IDU within the previous five years, were eligible to start ART, understood the study procedures, and signed informed consent. Since there were few female drug users in the clinic population at the time of recruitment, the study population was restricted to men only. Study participants are followed every 6 months for 3 years. For the current analysis, we include data from the baseline, 6 month, and 12 month study visits. One participant was excluded from this analysis because of missing questionnaire data at baseline.

This study was reviewed and approved by the Institutional Review Boards of the Tufts School of Medicine and the Hanoi School of Public Health.

2.2. Data Collection. Data collected at each study visit included a brief physical examination, body composition measurements, dietary intake, and a lifestyle questionnaire. The lifestyle questionnaire elicited information on sociodemographics; medical history; alcohol, tobacco, and drug use; use of ART and other prescribed medications; adherence to ART; food insecurity. Adherence to ART was assessed by the patient's subjective rating of how well he was able to take all of his prescribed HIV medications in the past 30 days using a 5-point Likert scale with responses of excellent, very good, good, fair, or poor [11]. Food insecurity was measured using a modified version of the USDA's short form of the household food security scale [12]. Dietary intake was estimated by a 24-hour recall. Anthropometric assessments included weight, height, and skinfold measurements (triceps, suprailiac, and subscapular). Fat mass was calculated using the equations of Durnin and Womersley [13]. Fat-free mass (FFM) was obtained by subtracting fat mass from total body weight. Dietary intake and anthropometric assessments were administered by study personnel who were trained and standardized regularly by a research dietitian. At each study visit, blood was collected for the determination of complete blood count, CD4 cell count, and HIV viral load.

2.3. Statistical Analysis. Using a repeated measures regression model, we identified clinical and nutritional predictors of weight change over two consecutive 6-month intervals (Interval 1: pre-ART to 6 months post-ART; and Interval 2: 6 to 12 months post-ART). The unit of analysis was personintervals. The term "interval baseline" is defined as the baseline (pre-ART) visit for Interval 1 and the 6 month visit for Interval 2. The outcome of interest was weight change over the interval.
We examined several time-varying predictors of weight change including CD4 count (cells/ $\mu \mathrm{L})$, log viral load (copies/ml), drug use in the previous 6 months (yes/no), hepatitis C coinfection (yes/no), TB coinfection (yes/no), energy intake (total kilocalories from food and supplements), carbohydrate intake (grams), fiber intake (grams and grams/kg body weight), protein intake (grams and grams/kg body weight), total fat intake (grams), food insecurity (yes/no), adherence to ART (Excellent/Very Good versus Good/Fair/Poor), intake of liquid supplements (yes/no), and general symptoms of illness (thrush, mouth sores, nausea, vomiting, diarrhea, stomach pain, and fever). Liquid supplement use was defined as any report of intake of Ensure liquid supplements, Oresol (oral glucose-electrolyte solution), glucose, or sweetened condensed milk which was not part of a meal or other drink. Symptoms of illness were categorized as "yes" only if participants reported that they were bothered by the symptom moderately, quite a bit, or extremely. Moderate/heavy drinking was categorized as "yes" when participants drank $\geq 4$ days per week and/or had 3 or more drinks on the days they drank. All of these variables were measured at the interval baseline, with the exception of adherence to ART, which was taken at the end of the interval since patients were reporting their adherence levels during the previous 6 months. Tobacco smoking (yes/no) was assessed at the baseline visit only. In addition, changes in CD4+ cell count and log viral load over the interval were examined as potential correlates of weight change, while baseline (pre-ART) body mass index (BMI; weight (in $\mathrm{kg}$ )/height (in $\left.\mathrm{m}^{2}\right)$ ) was examined as a potential confounder.

All statistical analyses were carried out using the SAS statistical software (SAS Institute, Cary, NC, Version 9.2). Repeated measures analyses were performed using PROC MIXED in SAS. To determine if the predictors of weight change differed by interval, interaction terms of each potential predictor with an indicator variable for "interval" were examined in the models. Since several of these interaction terms were significant in the final model, for ease of interpretation, the model results are presented separately by interval in Table 3 with standard errors and $P$-values obtained from the Estimate statement in PROC MIXED.

\section{Results}

Table 1 shows the sociodemographic and clinical characteristics for the 99 men that were assessed at the baseline study visit only. The average age was 32 years. The majority $(69 \%)$ were married and had 10 or more years of education (79\%). Approximately one-third had been imprisoned in their lifetime. Nearly $80 \%$ reported current tobacco smoking and almost all of the men (92\%) tested positive for Hepatitis $\mathrm{C}$ infection. All participants were started on ART approximately 2 weeks after study entry. Most (59\%) were started on ZDV/3TC/EFV. For this analysis, we did not take into account any treatment changes or interruptions over the 12 month followup period, which were very few.

By one year after starting ART, 8 men had died ( 7 in the first 6 months), 10 men were lost to follow-up, 3 were jailed, and 4 had transferred to another clinic. Thus, of the 
TABLE 1: Characteristics measured at baseline study visit only for 99 HIV-positive men recruited from the National Hospital of Tropical Diseases (NHTD) in Hanoi, Vietnam.

\begin{tabular}{lc}
\hline Baseline characteristic & Mean \pm SD or N(\%) \\
\hline Age & $31.7 \pm 4.8$ \\
Marital Status ${ }^{1}$ & \\
$\quad$ Never married & $22(22 \%)$ \\
$\quad$ Married & $68(69 \%)$ \\
$\quad$ Divorced/Sep/Widowed & $8(8 \%)$ \\
Education & \\
$<9$ years & $21(21 \%)$ \\
10-12 years & $43(43 \%)$ \\
Vocational & $18(18 \%)$ \\
University or more & $17(17 \%)$ \\
Jail or prison (ever) & $31(31 \%)$ \\
Tobacco smoking & $77(79 \%)$ \\
Hepatitis C & $91(92 \%)$ \\
Initial ART Regimen & \\
ZDV/3TC/EFV & $48(59 \%)$ \\
ZDV/3TC/NVP & $19(23 \%)$ \\
D4T/3TC/NVP & $9(11 \%)$ \\
D4T/3TC/EFV & $4(5 \%)$ \\
DDI/ABC/KAL & $1(1 \%)$ \\
\hline
\end{tabular}

Abbreviations: ZDV: zidovudine; 3TC, lamivudine; EFV: efavirenz; NVP: Nevirapine; D4T: stavudine; ABC: abacavir; KAL: kaletra.

$1_{n}=98$.

${ }^{2} n=81$.

100 patients enrolled, 81 and 75 had data available for analysis from their 6 and 12 month follow-up visits, respectively. Table 2 shows participant characteristics that were measured at each of the three study visits. Nearly half (47\%) reported using any drugs (injection or noninjection) and $24 \%$ reported injection drug use in the six months prior to recruitment. Rates decreased over time for both types of drug use. While rates of moderate/heavy alcohol use decreased slightly, rates of light drinking increased substantially over time. There were very few reports of food insecurity at any of the study visits. Both CD4 counts and viral load improved over time. Body mass index (BMI) also improved over time. At baseline, BMI was less than $18.5 \mathrm{~kg} / \mathrm{m}^{2}$ for $39 \%$ of our study participants, compared with $23.5 \%$ among men of the same age group living in the region [14]. By 12 months post-ART, only $17 \%$ of the men had BMI levels $<18.5 \mathrm{~kg} / \mathrm{m}^{2}$. Reports of general symptoms of illness decreased from preto post-ART, while energy intake remained constant. The proportion adhering well to ART decreased from 6 to 12 months post-ART.

3.1. Treatment Outcomes at 6 and 12 Months after ART Initiation. Table 3 shows the average change for several continuous variables over each interval. Both immunological and virological responses were favorable. The mean increase in CD 4 counts was 66 cells $/ \mu \mathrm{L}$ in Interval 1 and 32 cells $/ \mu \mathrm{L}$ in Interval 2, resulting in mean CD4 levels of 160 cells $/ \mu \mathrm{L}$ $($ median $=137$ cells $/ \mu \mathrm{L})$ after six months on treatment and
TABLE 2: Characteristics measured at each study visit for 99 HIVpositive men recruited from the National Hospital of Tropical Diseases (NHTD) in Hanoi, Vietnam.

\begin{tabular}{|c|c|c|c|}
\hline & \multicolumn{3}{|c|}{ Study visit (Mean \pm SD or N (\%)) } \\
\hline & $\begin{array}{c}\text { Baseline } \\
(\text { pre-ART) } \\
(n=99)\end{array}$ & $\begin{array}{l}6 \text { month } \\
(n=81)\end{array}$ & $\begin{array}{l}12 \text { month } \\
(n=75)\end{array}$ \\
\hline $\begin{array}{l}\text { Any drug use in last } 6 \\
\text { months }^{1}\end{array}$ & $47(47 \%)$ & $26(33 \%)$ & $22(30 \%)$ \\
\hline $\begin{array}{l}\text { Injection drug use in } \\
\text { last } 6 \text { months }{ }^{1}\end{array}$ & $24(24 \%)$ & $10(13 \%)$ & $8(11 \%)$ \\
\hline \multicolumn{4}{|l|}{ Alcohol $^{2}$} \\
\hline Nondrinker & $52(53 \%)$ & $30(38 \%)$ & $23(31 \%)$ \\
\hline Light drinker & $26(27 \%)$ & $36(45 \%)$ & $40(54 \%)$ \\
\hline $\begin{array}{l}\text { Moderate or heavy } \\
\text { drinker }\end{array}$ & $20(20 \%)$ & $14(18 \%)$ & $11(15 \%)$ \\
\hline Food insecurity ${ }^{2}$ & $5(5 \%)$ & $2(3 \%)$ & $3(4 \%)$ \\
\hline CD4 count (cells $/ \mu \mathrm{L})$ & $96.7 \pm 67.6$ & $\begin{array}{c}160.3 \pm \\
114.7\end{array}$ & $\begin{array}{c}194.6 \pm \\
144.5\end{array}$ \\
\hline CD $4<200$ cells $/ \mathrm{uL}$ & $88(89 \%)$ & $61(75 \%)$ & $46(61 \%)$ \\
\hline $\begin{array}{l}\text { Log viral load } \\
(\text { copies } / \mathrm{mL})^{3}\end{array}$ & $4.9 \pm 1.0$ & $2.1 \pm 1.0$ & $1.9 \pm 0.8$ \\
\hline $\begin{array}{l}\text { Viral load }<1000 \\
\text { copies }(\%)^{3}\end{array}$ & $7(7 \%)$ & $70(86 \%)$ & $67(92 \%)$ \\
\hline Weight (kg) & $52.9 \pm 7.1$ & $56.5 \pm 7.8$ & $57.3 \pm 8.0$ \\
\hline BMI $\left(\mathrm{kg} / \mathrm{m}^{2}\right)$ & $19.1 \pm 2.1$ & $20.4 \pm 2.3$ & $20.8 \pm 2.3$ \\
\hline \multicolumn{4}{|l|}{ BMI categories } \\
\hline$<17.0 \mathrm{~kg} / \mathrm{m}^{2}$ & $15(15 \%)$ & $4(5 \%)$ & $0(0 \%)$ \\
\hline $\begin{array}{l}17.0 \text { to } \\
<18.5 \mathrm{~kg} / \mathrm{m}^{2}\end{array}$ & $24(24 \%)$ & $15(19 \%)$ & $13(17 \%)$ \\
\hline 18.5 to $<20 \mathrm{~kg} / \mathrm{m}^{2}$ & $26(26 \%)$ & $22(27 \%)$ & $16(21 \%)$ \\
\hline$\geq 20.0 \mathrm{~kg} / \mathrm{m}^{2}$ & $34(34 \%)$ & $40(49 \%)$ & $46(61 \%)$ \\
\hline Bothersome nausea $^{1}$ & $46(46 \%)$ & $11(14 \%)$ & $15(20 \%)$ \\
\hline $\begin{array}{l}\text { Bothersome } \\
\text { Diarrhea }^{1}\end{array}$ & $20(20 \%)$ & $1(1 \%)$ & $1(1 \%)$ \\
\hline Bothersome fever ${ }^{1}$ & $62(63 \%)$ & $12(15 \%)$ & $13(18 \%)$ \\
\hline $\begin{array}{l}\text { Energy intake } \\
(\text { kcals/day })^{4}\end{array}$ & $2108 \pm 755$ & $2015 \pm 799$ & $2192 \pm 780$ \\
\hline $\begin{array}{l}\text { Excellent/Very Good } \\
\text { Adherence to ART }\end{array}$ & - & $60(76 \%)$ & $51(69 \%)$ \\
\hline $\begin{array}{l}{ }^{1} n=80 \text { for } 6 \text { month visit } \\
{ }^{2} n=98 \text { for baseline, } n= \\
\text { visit. } \\
{ }^{3} n=73 \text { for } 12 \text { month vis } \\
{ }^{4} n=69 \text { for } 12 \text { month vis } \\
{ }^{5} n=79 \text { for } 6 \text { month visit }\end{array}$ & $\begin{array}{l}\text { and } n=74 \text { for } \\
=80 \text { for } 6 \text { mon }\end{array}$ & $\begin{array}{l}\text { month visit. } \\
\text { visit, and } n=\end{array}$ & for 12 month \\
\hline
\end{tabular}

195 cells $/ \mu \mathrm{L}$ (median $=171$ cells $/ \mu \mathrm{L})$ after 12 months. However, at the end of 12 months on treatment, $61 \%(46 / 75)$ still had CD4 counts $<200,19 \%$ had CD4 <100 (14/75), and $3 \%(2 / 75)$ had $\mathrm{CD} 4<50$ cells $/ \mu \mathrm{L}$ (data not shown). HIV viral load levels decreased by nearly three logs in the first six months and remained stable over the next 6 months. By 12 months of treatment, $92 \%$ had viral load levels $<1000$ copies $/ \mathrm{mL}$ and $77 \%$ had levels $<50$ copies $/ \mathrm{mL}$. 
TABLE 3: Average changes in selected variables over each six month interval.

\begin{tabular}{|c|c|c|}
\hline & \multicolumn{2}{|c|}{ Mean $\pm \mathrm{SD}(P$-value $)$} \\
\hline & Interval 1: & Interval 2: \\
\hline & pre-ART to 6 months post-ART & 6 to 12 months post-ART \\
\hline & $(N=81)$ & $(N=75)$ \\
\hline CD4 count $($ cells/ $\mu \mathrm{L})$ & $65.6 \pm 97.2(<0.001)$ & $32.4 \pm 101.0(0.01)$ \\
\hline Log Viral Load (copies/mL) & $-2.8 \pm 1.5(<0.001)$ & $-0.1 \pm 0.9(0.28)$ \\
\hline Weight (kg) & $3.1 \pm 4.8(<0.001)$ & $0.8 \pm 3.0(0.02)$ \\
\hline$\%$ Weight change & $6.2 \pm 9.6(<0.001)$ & $1.3 \pm 5.5(0.01)$ \\
\hline BMI $\left(\mathrm{kg} / \mathrm{m}^{2}\right)$ & $1.1 \pm 1.7(<0.001)$ & $0.3 \pm 1.1(0.05)$ \\
\hline Fat-free mass $(\mathrm{kg})$ & $1.5 \pm 3.0(<0.001)$ & $0.5 \pm 2.3(0.05)$ \\
\hline Fat-free mass $(\%)$ & $-1.7 \pm 4.0(<0.001)$ & $-0.3 \pm 3.2(0.48)$ \\
\hline Fat mass $(\mathrm{kg})$ & $1.6 \pm 2.9(<0.001)$ & $0.3 \pm 2.3(0.27)$ \\
\hline Fat mass $(\%)$ & $1.7 \pm 4.0(<0.001)$ & $0.3 \pm 3.2(0.48)$ \\
\hline
\end{tabular}

Average weight and BMI increased significantly over both intervals, but the increases were more substantial in the initial 6 months after starting ART. The increase in weight was approximately equally divided between increases in fat and fat-free mass. Percent fat increased significantly only in the first 6 months.

3.2. Predictors of Weight Change. Many of the potential predictors we examined were associated with weight change in the unadjusted regression models (data not shown). In the final multivariate model, several predictors remained significantly and independently associated with weight change. These variables are listed in Table 4 . In cases where "interval" was considered a significant effect modifier (all predictors except for tobacco smoking), coefficients are presented and interpreted separately for Interval 1 and Interval 2 as described in Methods. In Interval 1, all of these predictors were significantly associated with a positive weight change, except for moderate/heavy drinking, which was significantly associated with negative weight change. In Interval 2, however, none of these covariates were associated with weight change, except for CD $4<200$ at the interval baseline, which was now significantly associated with negative weight change. Tobacco smoking had the same negative effect on weight change in both intervals $(\beta=-1.2 \mathrm{~kg} ; P=.02)$. Energy intake and food insecurity were not independently associated with weight change in either interval.

Figures 1(a)-1(d) shows the net weight gain/loss by interval for presence and absence of several of the covariates as predicted by the final regression model. For each figure, the values assumed for the other covariates in the model are delineated in the figure title. Figure 1(a) shows that participants with CD4 $<200$ at the start of ART are predicted to gain, on average, over $2.6 \mathrm{~kg}$ in the first 6 months of treatment, while those with CD4 $\geq 200$ are predicted to lose over $0.8 \mathrm{~kg}$ during that same interval. This difference of nearly $3.5 \mathrm{~kg}$ is statistically significant. In Interval 2, the reverse is seen with significantly larger weight gain among those with CD4 counts $\geq 200$. Figure 1 (b) shows the predicted net weight changes by interval for those with Excellent/Very Good adherence to ART compared to those with Good/Fair/Poor adherence. In the first 6 months of ART, those with Excellent/Very Good adherence are predicted to gain $2.6 \mathrm{~kg}$ weight, while those reporting Good/Fair/Poor adherence are predicted to lose $0.4 \mathrm{~kg}$. In the second interval, only very slight weight losses are predicted for both levels of adherence. In Figure 1(c), we see that moderate to heavy alcohol intake has a significant negative effect on weight gain in the first six months after initiation of ART with none/light drinkers gaining $2.6 \mathrm{~kg}$ of weight, while moderate/heavy drinkers gained only $0.1 \mathrm{~kg}$. There was, however, no difference in weight change by alcohol intake 6 to 12 months later. Conversely, use of liquid supplements had a significant positive effect on weight gain in Interval 1 (people taking liquid supplements gained $5.2 \mathrm{~kg}$ versus $2.6 \mathrm{~kg}$ weight gain in all others), but not in Interval 2 (Figure $1(\mathrm{~d})$ ).

\section{Discussion}

Overall, ART outcomes were encouraging in this population of Vietnamese men with a history of IDU. CD4 counts increased by 66 cells/ $\mu \mathrm{L}$ after six months and by 98 cells $/ \mu \mathrm{L}$ after 12 months. HIV viral load decreased significantly, resulting in $92 \%$ of the men being virally suppressed $(<1000$ copies/ml) after 12 months on therapy. Significant increases in weight were observed, particularly in the first 6 months of therapy.

The pattern of weight gain we observed appears to be consistent with previous reports, with the highest rate of weight gain occurring in the first six months after ART initiation, then stabilizing afterwards. In a combined analysis of patients in ART programs in Cambodia $(n=2451)$ and Kenya $(n=2618)$, Madec et al. [8] observed a similar pattern of weight gain, although patients in that study continued to gain weight up to 12 months post-ART before weights stabilized. The amount of weight gain we observed over the initial six months $(3.1 \pm 4.8 \mathrm{~kg})$ is also similar to reports from other populations. In 488 patients initiating ART in four African countries (Ethiopia, Kenya, Rwanda, and Uganda), an average weight gain of $3.9 \pm 5.1 \mathrm{~kg}$ over 6 months was 


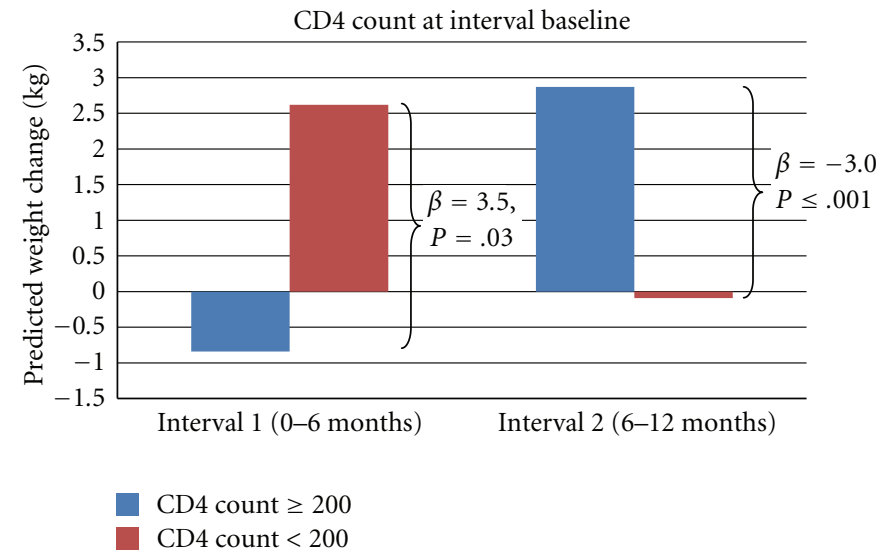

(a)

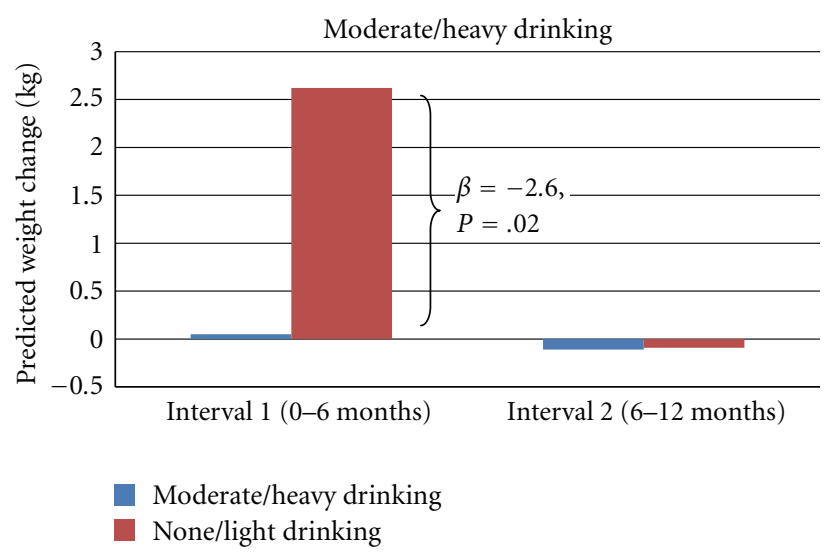

(c)

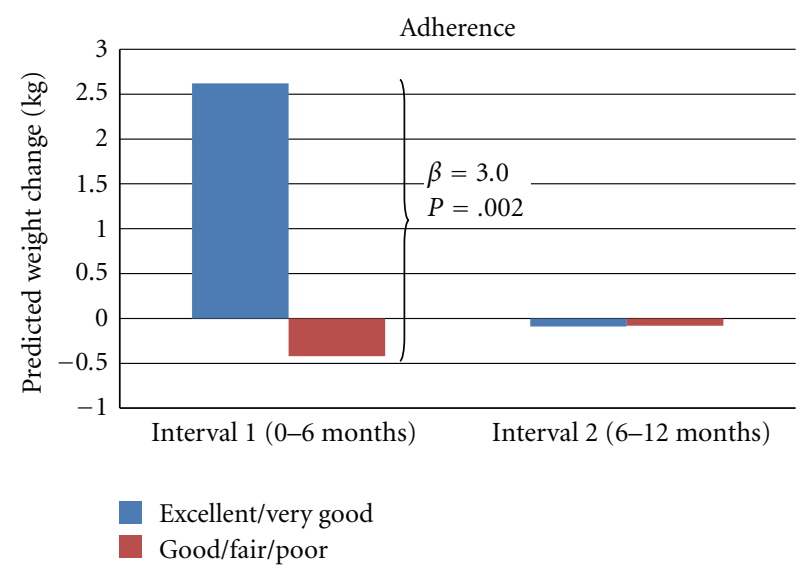

(b)

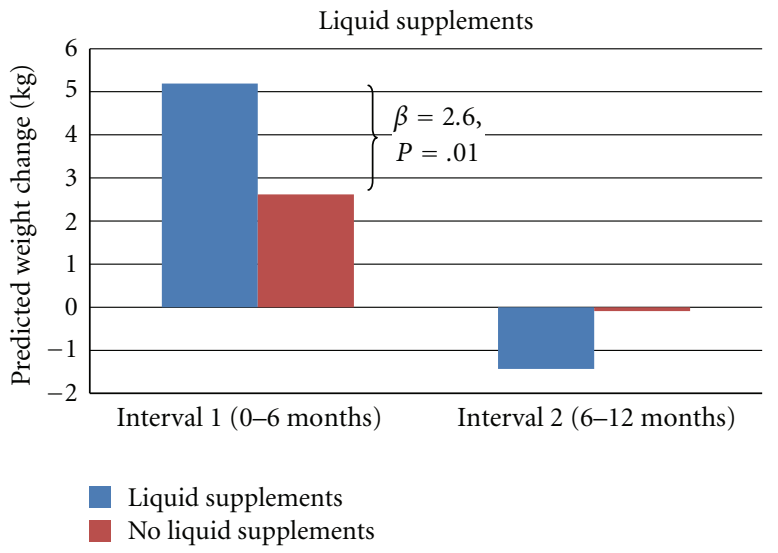

(d)

Figure 1: Predicted weight changes by interval for men with and without specific characteristics. (a) Values for other covariates are: Adherence $=$ Excellent $/$ Very Good, Nausea $=$ no, Moderate $/$ Heavy Drinking $=$ no, Liquid supplements $=$ no, and Tobacco smoking $=$ yes. $(b)$ Values for other covariates are: CD $4<200=$ yes, Nausea $=$ no, Mod/Heavy Drinking $=$ no, Liquid supplements=no, and Tobacco smoking $=$ yes. (c) Values for other covariates are: CD4 $<200=$ yes, Adherence $=$ Excellent/Very good, Nausea $=$ no, and Liquid supplements $=$ no, and Tobacco smoking = yes. $(\mathrm{d})$ Values for other covariates are CD4 $<200=$ yes, Adherence $=$ Excellent/Very good, Nausea $=$ no, and Moderate/Heavy drinking $=$ no, and Tobacco smoking $=$ yes.

TABLE 4: Coefficients derived from final multivariate model predicting weight change, accounting for effect modification by Interval.

\begin{tabular}{|c|c|c|c|}
\hline & \multicolumn{2}{|c|}{ Difference in weight change $(\beta) \pm \operatorname{SE}(P$-value $)$} & \multirow[t]{2}{*}{$P$-value for interaction term } \\
\hline & Interval 1 & Interval 2 & \\
\hline Intercept & $-2.7 \pm 1.8(.14)$ & $4.1 \pm 0.9(<.001)$ & 0.001 \\
\hline CD $4<200$ cells $/ \mu \mathrm{L}$ (yes/no) & $3.5 \pm 1.5(.03)$ & $-3.0 \pm 0.7(<.001)$ & $<0.001$ \\
\hline $\begin{array}{l}\text { Adherence to HIV meds } \\
\text { (Excellent/Very Good versus } \\
\text { Good/Fair/Poor) }\end{array}$ & $3.0 \pm 0.9(.002)$ & $-0.01 \pm 0.7(.98)$ & 0.01 \\
\hline Nausea (yes/no) & $2.2 \pm 0.8(.006)$ & $-1.3 \pm 0.8(.13)$ & 0.005 \\
\hline $\begin{array}{l}\text { Moderate/Heavy Drinker } \\
\text { (yes/no) }\end{array}$ & $-2.6 \pm 1.0(.02)$ & $-0.02 \pm 0.8(.98)$ & 0.06 \\
\hline Liquid supplements (yes/no) & $2.6 \pm 1.0(.01)$ & $-1.3 \pm 1.5(.39)$ & 0.05 \\
\hline Tobacco smoking & \multicolumn{2}{|c|}{$-1.2 \pm 0.5(.02)$} & 0.17 \\
\hline
\end{tabular}

Interaction term (Tobacco smoking $*$ Interval) was dropped from the final model due to nonsignificant $P$-value. Coefficient shown is from main effect of tobacco smoking only. 
recorded [15]. In India, investigators reported an average weight gain of $2.8 \pm 5.4 \mathrm{~kg}$ over 6 months in 190 patients starting ART [16]. In 185 Nigerian patients followed up for two years, the average weight of the group increased from $52 \mathrm{~kg}$ pre-ART to $59 \mathrm{~kg}$ post-ART [17]. In comparison, the average weight in our cohort increased from $53 \mathrm{~kg}$ pre-ART to $57 \mathrm{~kg}$ after one year post-ART.

We also observed some differences in our population compared to previous publications. In terms of BMI, Barth et al. [18] reported an average BMI increase of $2.4 \mathrm{~kg} / \mathrm{m}^{2}$ after 6 months on ART and $3.5 \mathrm{~kg} / \mathrm{m}^{2}$ after 12 months among patients initiating ART in South Africa. We observed an average BMI increase of only $1.1 \mathrm{~kg} / \mathrm{m}^{2}$ after 6 months and $1.4 \mathrm{~kg} / \mathrm{m}^{2}$ after 12 months post-ART. One reason for this difference could be that BMI at baseline was slightly higher (less room to improve) in our participants (median = $19.2 \mathrm{~kg} / \mathrm{m}^{2}$ ) compared to the male participants in the Barth study $\left(\right.$ median $\left.=18.6 \mathrm{~kg} / \mathrm{m}^{2}\right)$; however patients in the Barth study achieved a BMI level of $23.4 \mathrm{~kg} / \mathrm{m}^{2}$ after 12 months on ART, whereas our participants achieved a BMI level of only $20.8 \mathrm{~kg} / \mathrm{m}^{2}$ after 12 months. Another reason is that the Barth study focused on a population where the primary mode of HIV transmission is heterosexual, whereas ours was a population of injection drug users where other related risk factors (behavioral and/or biological) could inhibit optimal weight gain. In addition, although two previous studies reported that patients with lower BMI at ART initiation $(\leq 16$ or $\leq 17$ ) had larger weight gains than those with higher BMI $[8,19]$, baseline BMI was not associated with weight change in our population.

We found several significant predictors of weight gain, particularly in the first six months after ART initiation. Patients with more advanced HIV infection at baseline (CD4 cell counts $<200$ cells $/ \mu \mathrm{L}$ ) were more likely to have positive weight changes in the first six months of therapy, likely due to the beneficial effects of ART. However, six months after start of ART, patients with CD $4<200$ cells/ $\mu \mathrm{L}$ (a sign of continued immunosuppression) had significantly less weight change over the following six months compared to those with CD4 $\geq 200$. The vast majority (92\%) of our patients started ART with CD 4 counts $<200$ cells $/ \mu$ L. Of these, $87 \%$ of patients whose CD 4 counts improved to $\geq 200$ cells $/ \mu \mathrm{L}$ after 6 months of therapy gained weight, while only $48 \%$ of those with continued immunosuppression after 6 months gained weight.

In our cohort, "Excellent" to "Very Good" adherence to ART medications was significantly associated with positive weight change in the first six months of therapy. Similarly, Ross-Degnan et al. found that adherence was significantly associated with weight gain over the first 9 months after ART initiation in four African countries [15]. In our study, after six months of therapy, excellent/very good adherence was no longer independently associated with positive weight change after taking into account the positive effect of CD4 counts rising to $\geq 200$ cells $/ \mu \mathrm{L}$.

We found that bothersome nausea at baseline (reported by $49 \%$ of participants) was associated with weight gain in the first 6 months of ART. While this may seem to be counterintuitive, we can speculate that having bothersome nausea at baseline (pre-ART) is a symptom of illness contributing to reduced food intake, and when these patients initiate ART their symptoms resolve and they are able to eat more and gain more weight. In the second interval, the $15 \%$ who reported bothersome nausea (post-ART) had a negative weight change (although not statistically significant $(P=.13))$. At this point in time, continued nausea or nausea from side effects of the medications may inhibit a patients' ability to gain weight.

The use of liquid supplements was a significant predictor of weight gain in the first six months of ART and therefore may have potential as a nutritional intervention for weight gain (or reducing weight loss) in this population. No other dietary factors were associated with weight change, indicating that a dietary supplement may be necessary. Liquid supplements were primarily Ensure or Oresol (a glucose-electrolyte solution). While Ensure is known as a balanced nutritional supplement, Oresol is generally used as a treatment for dehydration or diarrhea and has little nutritional value beyond its sugar and electrolyte content. The other two types of liquid supplements that were reported in this population (glucose solution and sweetened condensed milk) contribute high amounts of calories from carbohydrates and sugars assisting in weight gain, but have minimal nutrient content. More in-depth information is needed before planning a nutritional intervention with a liquid supplement, such as the reasons why patients were taking these supplements, how much and how often they were taking them, and whether they were taking them on their own or as prescribed by a doctor. Fundamentally, we still need to understand whether weight gain by any means is associated with improved outcomes on ART, or if nutritionally balanced supplements are more likely to be successful. We were not able to examine this in our population because we did not have enough patients taking each of the different types of supplements.

Another interesting finding from our study is that alcohol intake was associated with negative weight gain in the first six months after ART initiation in the first interval, but not the second. While nutritional status in alcoholics has been described in the United States and Western Europe [20$24]$, the nutritional impact of alcohol abuse has not been studied in a population with marginal nutritional status such as our population of drug users with HIV in Vietnam. In addition, the effects of alcohol abuse on the liver are more marked in persons with chronic viral hepatitis [25-27]. This is of particular concern in our population where $92 \%$ are coinfected with Hepatitis C. Twenty percent of our population reported moderate to heavy amounts of alcohol use at baseline and this group had significantly less weight gain than non- to light drinkers. Further research is needed on the specific nutritional, biological, and/or behavioral effects of alcohol use in this population to determine the mechanism through which it reduces weight change. Similarly tobacco smoking had a significantly negative effect on weight change in both intervals. Since the vast majority $(\sim 80 \%)$ of our study population reported tobacco smoking at baseline, this would be another high-priority area for research, including the testing of smoking cessation interventions. 
Our study had some limitations. First, our results may not be generalizable to populations where injection drug use is not the major mode of HIV transmission. Injection drug users may have additional complications predisposing to weight loss, such as cytokine-mediated weight loss due to sepsis and infections and/or psychiatric comorbidities (e.g., depression, euphoria, behavioral abnormalities, and memory disturbances) that may affect food choices and eating patterns. Second, this study did not take into account the effect of other medical comorbidities potentially associated with weight change, such as opportunistic infections, inflammatory states, cancers, and malabsorption. We were not able to obtain standardized clinical diagnoses of medical co-morbidities in this study as diagnostic tests for these conditions are not generally available to this patient population and the physicians do not routinely look for these during their ART visits. However, we did include self-reports of TB and Penicillium marneffei diagnoses on the questionnaire, but found very few participants who reported these. Finally, a single 24-hour dietary recall to assess dietary intake is a limitation as this may not accurately reflect typical daily intake over the previous 6 or 12 months. We felt that this method for assessment of dietary intake was best suited for this population in Vietnam as it is less of a burden to study participants compared to the food diaries, and we were not aware of a validated food frequency questionnaire in Vietnam. We did ask participants whether the 24-hour recall was reflective of their usual intake, considerably more, or considerably less than their usual intake and $70-80 \%$ of participants at 6 and 12 months reported that it was reflective of their usual intake.

In summary, we found that significant weight gain was achieved in the first 6 months after ART initiation, and then stabilized over the next 6 months. While this is a positive result, some improvements are still needed. Although 39\% were classified as underweight at baseline, only $28 \%$ of our participants gained at least $10 \%$ of their baseline weight (an indicator of treatment success used by some ART clinics) by six months after ART initiation, and only one additional person reached this endpoint by 12 months. More research is needed to determine why weight gain did not continue after 6 months of therapy, particularly when a significant proportion of patients in this population were still underweight (BMI < 18.5). In addition, the magnitude of CD4 change over 6 and 12 months of ART use was less than that reported in other populations and this requires further investigation. The fact that having a CD $4<200$ cells $/ \mu \mathrm{L}$ at 6 months post-ART was associated with continued weight loss (or a reduction in weight gain) in the following six months suggests that efforts should be made to diagnose and treat patients earlier, before their CD4 levels drop too far below 200 cells $/ \mu \mathrm{L}$ that they remain under this threshold after six months of therapy.

This study is the first step towards developing targeted interventions to improve nutritional and immunological outcomes on ART in drug users in Vietnam. We identified several potential areas for interventions to promote weight gain in this population. Studies are still needed to determine whether improving BMI prior to ART initiation will reduce early mortality rates.

\section{Author's Contribution}

M. Tang drafted the paper and was involved in all aspects of the study. H. B. Sheehan and N. Terrin conducted statistical analysis and assisted in the manuscript preparation. K. Dong and T. T. M. Lien trained the study staff, were involved in data management, and assisted in paper preparation. D. V. Duong, N. V. Trung, and N. D. Hien were involved in the conception, design, and implementation of the study. M. R. Jordan and C. A. Wanke provided critical and substantive reviews of the final manuscript.

\section{Conflict of Interests}

There is no conflict of interests to declare.

\section{Acknowledgments}

This work was supported by National Institutes of Health (NIH) Grants R01-DA022163, P30-DA013868, and K23AI074423. The authors thank Dr. Nguyen Thi Bich Ha, Dr. Nguyen Dung, and all of the clinical staff at the National Hospital of Tropical Diseases (NHTD) in Hanoi for their hard work and dedication to this study and the study participants; Dr. Nguyen Van Kinh (NHTD) and Dr. Sherwood Gorbach (Tufts) for their continued support of this project; Jeanette Queenan (Tufts) for analyzing the dietary recalls; all of study volunteers for their participation.

\section{References}

[1] M. Silva, P. R. Skolnik, S. L. Gorbach et al., "The effect of protease inhibitors on weight and body composition in HIVinfected patients," AIDS, vol. 12, no. 13, pp. 1645-1651, 1998.

[2] C. M. Shikuma, R. Zackin, F. Sattler et al., "Changes in weight and lean body mass during highly active antiretroviral therapy," Clinical Infectious Diseases, vol. 39, no. 8, pp. 12231230, 2004.

[3] J. S. A. Stringer, I. Zulu, J. Levy et al., "Rapid scale-up of antiretroviral therapy at primary care sites in Zambia: feasibility and early outcomes," Journal of the American Medical Association, vol. 296, no. 7, pp. 782-793, 2006.

[4] R. Zachariah, M. Fitzgerald, M. Massaquoi et al., "Risk factors for high early mortality in patients on antiretroviral treatment in a rural district of Malawi," AIDS, vol. 20, no. 18, pp. 23552360, 2006.

[5] A. Johannessen, E. Naman, B. J. Ngowi et al., "Predictors of mortality in HIV-infected patients starting antiretroviral therapy in a rural hospital in Tanzania," BMC Infectious Diseases, vol. 8, article 52, 2008.

[6] J. R. Koethe, M. I. Limbada, M. J. Giganti et al., "Early immunologic response and subsequent survival among malnourished adults receiving antiretroviral therapy in Urban Zambia," AIDS, vol. 24, no. 13, pp. 2117-2121, 2010.

[7] J. R. Koethe, A. Lukusa, M. J. Giganti et al., "Association between weight gain and clinical outcomes among malnourished adults initiating antiretroviral therapy in Lusaka, Zambia," Journal of Acquired Immune Deficiency Syndromes, vol. 53, no. 4, pp. 507-513, 2010.

[8] Y. Madec, E. Szumilin, C. Genevier et al., "Weight gain at 3 months of antiretroviral therapy is strongly associated with survival: evidence from two developing countries," AIDS, vol. 23, no. 7, pp. 853-861, 2009. 
[9] HIV and AIDS Data Hub for Asia-Pacific, "Asia-Pacific regional review of HIV," 2010, http://www.aidsdatahub.org/en/ regional-profile/regional-review.

[10] Ministry of Health-Vietnam Administration of HIV/AIDS Control, "Viet Nam HIV/AIDS Estimates and Projections, 2007-1012. Ha Noi, Vietnam: Family Health International (FHI/Viet Nam)," 2009, http://www.unaids.org.vn/sitee/images/stories/EPP\%20report\%20EN.pdf.

[11] M. Lu, S. A. Safren, P. R. Skolnik et al., "Optimal recall period and response task for self-reported HIV medication adherence," AIDS and Behavior, vol. 12, no. 1, pp. 86-94, 2008.

[12] S. J. Blumberg, K. Bialostosky, W. L. Hamilton, and R. R. Briefel, "The effectiveness of a short form of the household food security scale," American Journal of Public Health, vol. 89, no. 8, pp. 1231-1234, 1999.

[13] J. V. G. A. Durnin and J. Womersley, "Body fat assessed from total body density and its estimation from skinfold thickness: measurements on 481 men and women aged from 16 to 72 years," British Journal of Nutrition, vol. 32, no. 1, pp. 79-97, 1974.

[14] National Institute of Nutrition, General Nutrition Survey 2000, Hanoi Medical Publishing House, Hanoi, Vietnam, 2003.

[15] D. Ross-Degnan, M. Pierre-Jacques, F. Zhang et al., "Measuring adherence to antiretroviral treatment in resource-poor settings: the clinical validity of key indicators," BMC Health Services Research, vol. 10, article 42, 2010.

[16] S. Saghayam, N. Kumarasamy, S. Solomon et al., "Metabolic and body shape changes in a ART naive cohort initiating generic HAART in South India," in Proceedings of the 15th International AIDS Conference, Bangkok, Thailand, July 2004.

[17] H. O. Olawumi, P. O. Olatunji, A. K. Salami, L. Odeigah, and J. O. Iseniyi, "Effect of highly active antiretroviral therapy on CD4 count and weight in AIDS patients seen at the uith, Ilorin," Nigerian Journal of Clinical Practice, vol. 11, no. 4, pp. 312-315, 2008.

[18] R. E. Barth, J. T. M. van der Meer, A. I. M. Hoepelman et al., "Effectiveness of highly active antiretroviral therapy administered by general practitioners in rural South Africa," European Journal of Clinical Microbiology and Infectious Diseases, vol. 27, no. 10, pp. 977-984, 2008.

[19] J. R. Koethe, A. Lukusa, M. J. Giganti et al., "Association between weight gain and clinical outcomes among malnourished adults initiating antiretroviral therapy in Lusaka, Zambia," Journal of Acquired Immune Deficiency Syndromes, vol. 53, no. 4, pp. 507-513, 2010.

[20] C. L. Mendenhall, S. Anderson, and R. E. Weesner, "Proteincalorie malnutrition associated with alcoholic hepatitis. Veterans Administration cooperative study group on alcoholic hepatitis," American Journal of Medicine, vol. 76, no. 2, pp. 211-222, 1984.

[21] G. Addolorato, E. Capristo, A. V. Greco, G. F. Stefanini, and G. Gasbarrini, "Influence of chronic alcohol abuse on body weight and energy metabolism: is excess ethanol consumption a risk factor for obesity or malnutrition?" Journal of Internal Medicine, vol. 244, no. 5, pp. 387-395, 1998.

[22] Y. Falck-Ytter and A. J. McCullough, "Nutritional effects of alcoholism," Current Gastroenterology Reports, vol. 2, no. 4, pp. 331-336, 2000.

[23] L. Glória, M. Cravo, M. E. Camilo et al., "Nutritional deficiencies in chronic alcoholics: relation to dietary intake and alcohol consumption," American Journal of Gastroenterology, vol. 92, no. 3, pp. 485-489, 1997.

[24] J. M. Nicolas, R. Estruch, E. Antunez, E. Sacanella, and A. Urbano-Marquez, "Nutritional status in chronically alcoholic men from the middle socioeconomic class and its relation to ethanol intake," Alcohol and Alcoholism, vol. 28, no. 5, pp. 551558, 1993.

[25] Y. Benhamou, M. Bochet, V. Di Martino et al., "Liver fibrosis progression in human immunodeficiency virus and hepatitis C virus coinfected patients," Hepatology, vol. 30, no. 4, pp. 1054-1058, 1999.

[26] T. Poynard, P. Bedossa, and P. Opolon, "Natural history of liver fibrosis progression in patients with chronic hepatitis C," The Lancet, vol. 349, no. 9055, pp. 825-832, 1997.

[27] L. Martín-Carbonero, Y. Benhamou, M. Puoti et al., "Incidence and predictors of severe liver fibrosis in human immunodeficiency virus-infected patients with chronic hepatitis C: a European collaborative study," Clinical Infectious Diseases, vol. 38, no. 1, pp. 128-133, 2004. 


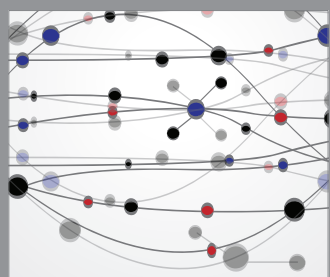

The Scientific World Journal
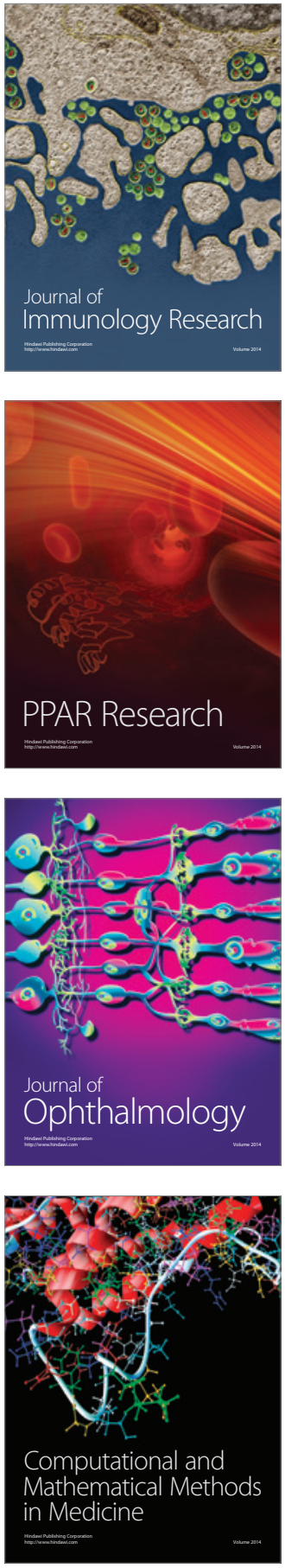

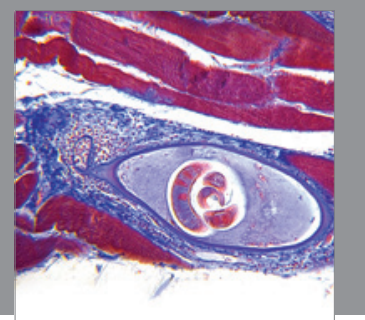

Gastroenterology

Research and Practice
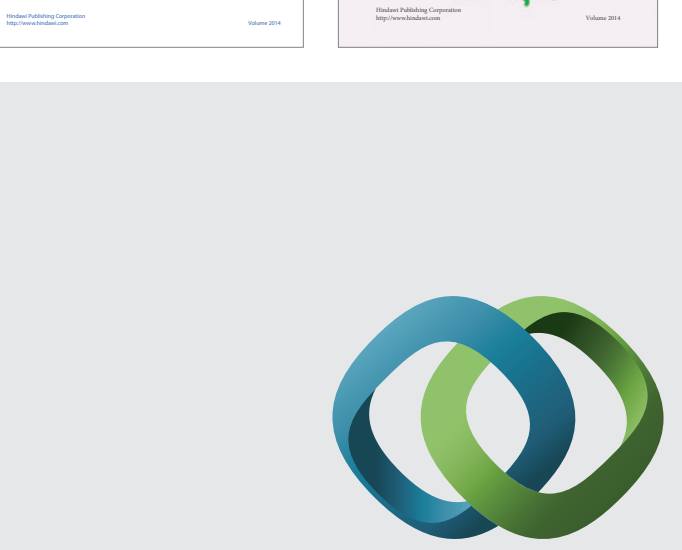

\section{Hindawi}

Submit your manuscripts at

http://www.hindawi.com
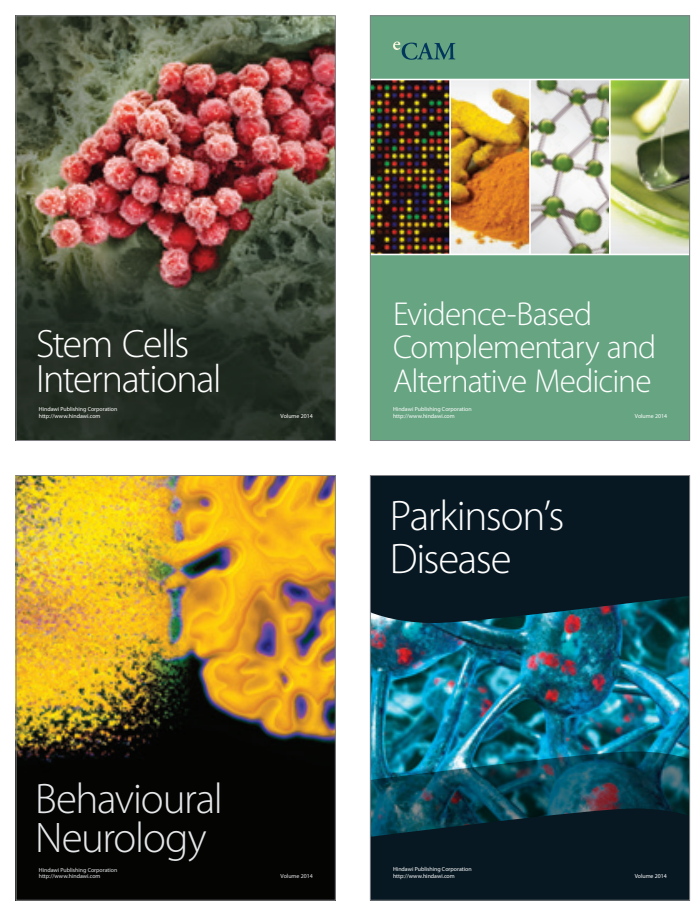

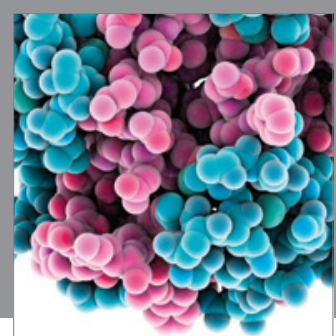

Journal of
Diabetes Research

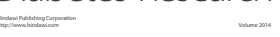

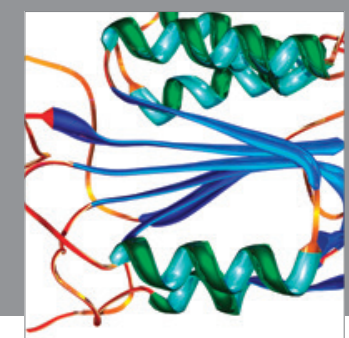

Disease Markers
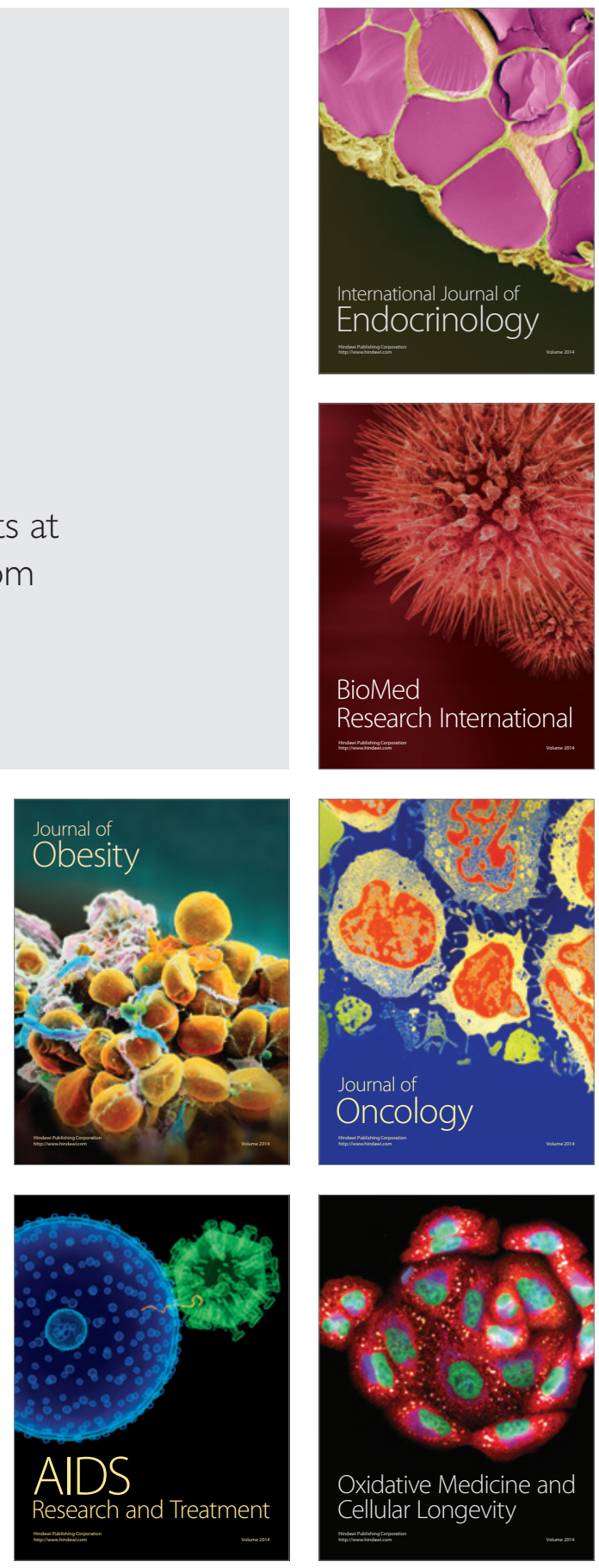